apart. At this stage the fibrils acquire more movement, the entropy increases and the procoss of imbibition goes on until, if the polymer be crosslinked, a steady and permanent oxtension is obtained. The conditions for equilibrium in such swelling are given by the thermodynamic relation:

$$
\Delta H=\Delta F-T A S
$$

Since $\Delta F=0$ at equilibrium, $\Delta H=-T A S$. 'The heat of mixing of two liquids is given approximately by the difforonco in their cohesive energies :

$$
\Delta H=K V\left(\sqrt{\frac{E_{1}}{V_{1}}}-\sqrt{\frac{E_{2}}{V_{2}}}\right)^{2}(1-V)^{2}
$$

where $E$, tho cohesive energy, is given by the latent heat of evaporation :

$$
E=L-R T
$$

The swelling powers and cohesive energies for a number of organic liquids when brought into contact with vulcanized rubber have been found to conform to this simple idea with remarkable exactness.

\title{
NEW SYSTEM OF ELECTRIFICATION FOR BRITISH RAILWAYS
}

\author{
By G. H. PLATT \\ King's College, University of London
}

$\mathrm{T}$ HE recent announcement by the British Transport Commission of its decision to adopt the 50 cycles/sec. single-phase alternating current system for future main-line clectrification of British Railways is of great interest to all in the electrical industry and of far-reaching importance to the nation as a whole.

The advantages of electrically operated railways are too well known to need elaborating here; but briefly they are :

(a) The greater power available enables faster services to be run and permits more frequent trains over any given track. This is most apparent in urban and suburban passenger services; but is equally important in handling the traffic over a busy main line.

(b) Above some particular traffic density, the cost per ton-mile is less than with other forms of motive power.

(c) Very much less coal is noeded than for stcam traction, owing to the much greater thermal efficiency of modern power stations than the steam locomotive. Moreover, the coal used in power stations is of inferior quality, and the use of nuclear energy will further save coal.

(d) The absence of smoke and dirt makes for general cleanliness.

Details of the British Transport Commission's scheme have already been published (March 1956). The new system is concerned principally with mainline electrification. The London 'Transport Executive and Southern Region systems are unaffected. Their form of power supply is the most suitable one for underground and suburban traffic, and the cost of converting that of the Southern Region is unwarranted for the amount of locomotive-hauled traffic involved.

For ordinary long-distance main lines, however, the conditions are quite different. 'The use of a.c. supply for electric railways offers great advantages from the transmission point of view in that a high voltage can be used on the overhead wire, and transformed down at the point of use, that is, on the locomotive. On the other hand, an a.c. motor has disadvantages for traction compared with its d.c. counterpart. A system using a.c. of low frequency $(15-25 \mathrm{c} / \mathrm{s}$.$) is in fairly wide use, but has the dis-$ advantage of requiring its own generating plant and supply network, entirely separate from those of the public supply, or else expensive frequency-changing substations employing rotating machinery. Rotating machines for the conversion of a.c. to d.c. have long been rendered obsolete by the development of the mercury arc rectifier, and the majority of electric railways using alternating current to-day convert the a.c. supply to d.c. at 1,500 or 3,000 volts in substations alongside the tracks. With main-line locomotives this means that heavy currents have to be collected. The weight of copper in the overhead system is thus considerable, the supports must be proportionally strong and the total cost is high.

By feeding the contact wire with a.c. at $25 \mathrm{kV}$. the current to be collected is greatly reduced and the whole overhead system can be made much lighter and cheaper. In addition, substations can be placed much farther apart so that fewer are noeded, and furthermore, the substations themselves are simpler and cheaper, containing only static transformers and switchgear. This is an important advantage, as the cost of the fixed installations does not vary greatly with the traffic density. Hence the use of a.c. supply may make it financially justifiable to electrify lines which would otherwise be uneconomic due to their lighter traffic.

In this connexion a special survey of the proposed Euston-Manchester-Liverpool route has shown that some startling economies will be effected by the use of a.c. This system will require twelve substations only instead of seventy for d.c., and need 68 per cent less copper and 17 per cent less steel for the overhead equipment. An additional saving in this case is that only seventeen instead of two hundred and fifty miles of $33 \mathrm{kV}$. feeder lines will be necessary to take the current from the Central Electricity Authority.

This change in supply has been made possible largely by the progress in rectifier design, which has now made it practicable to carry the rectifiers on the locomotives themselves. Those already in service mostly utilize mercury valves of the 'Ignitron' or similar type; but successful trials have been run recently on British Railways by a motor-coach employing a germanium rectifier. This is an important advance in this field.

The new system also offers greater scope for development in design and technique than other systems. With d.c. supply, the motive power must of necessity employ d.c. motors; but by bringing the a.c. right into the locomotive the maximum freedom is given for the development of its design. Locomotives 
with rectifiers, various types of converters and straight a.c. motors are in use experimentally in France, and some of these have been found to have special advantages for certain kinds of traffic.

The low-frequency, single-phase a.c. commutator motor is considered by some to have better charac. teristics than the d.c. machine for main-line work, and the development of the former to operate satisfactorily on $50 \mathrm{c} / \mathrm{s}$. has made considerable progress during the past few years in France. This type may yet become a serious rival to the d.c. series machine.

Up to now, however, the rectifier locomotive has given the most promising resultis, and has been found to have unexpected operating advantages over even its d.c. rival. On the Valenciennes-Thionville line, $B_{0}-B_{0}$ type mixed-traffic locomotives with 'Ignitron' rectifiers and having 84 tonnes adhesive weight haul freight trains of $\mathrm{I}, 400$ tonnes, whereas the absolute maximum loarting of a modern $1,500-\mathrm{V}$. d.c. locomotive of the same type and weight would be 900 tonnes only. This is due to improved adhesion characteristics at starting and at low speeds.

The motors used in rectifier locomotives are of the d.c. series type, specially designed to work satisfactorily on the pulsating output from the singlephase rectifiers. Biphase or 'full-wave' rectification is used, the output from which can be conside:ed as a smooth d.c. voltage having superimposed on it an alternating e.m.f. of comparable magnitude and a frequency of $100 \mathrm{c} / \mathrm{s}$. This introduces problems of commutation and heating in the motors; but by paying special attention to the design of the motors and including smootbing choles in the circuit the difficulty can be overcome satisfactorily. With the ordinary d.c. system the problem does not arise, since rectifiers having six or more phases are used and the a.c. component or 'ripple' is in consequence insignificant.
The cost of the rectifier locomotive, according to the French figures, is comparable with a d.c. machine of the same rating, both in first cost and maintenance. Allowing for the improved performance, the rectifier machine shows a considerable economy in operating a given service. The use of semiconductor rectifiers in the future should show an even greater saving. The above-mentioned British survey shows that sixty fewer locomotives will be needed for these services.

'The provision of sufficient clearances for a contactline voltage of 25,000 volts is not easy in Britain. In some tunnels the cost of providing clearances would be prohibitive, and therefore it is proposed to omploy a much lower voltage, namely, 6,600 volts, over certain sections, combined with the use of dual-voltage equipment.

The taking of large amounts of single-phase power from the public supply network suggests problems of unbalance on the three-phase system. Experience in France has shown that any disturbance has remained within acceptable limits, and no trouble is anticipated in Britain with its more heavily-loaded grid. The proposed scheme has the full concurrence of the Central Electricity Authority.

In addition to its major advantages, the use of a.c. supply simplifies very considerably the supply of power to locomotive auxiliaries, train lighting and heating, ete., a single transformer sufficing to provide supplies at any voltage required.

It is evident that the British Transport Commission's choice of the $50 \mathrm{c} / \mathrm{s}$. alternating current system is based on a balanced judgment of the many factors involved. The Commission's readiness to profit by the latest technical developments is to be highly commended.

I would like to thank the Chief Electrical Engineer of the British Transport Commission for placing information relating to the proposed developments at my dispossal.

\section{A NOTABLE BIOCHEMICAL JUBILEE}

N 1906 Arthur Harden and William John Young, of the Lister Institute of Preventive Medicine, made two communications to the Royal Society of London on the alcoholic ferment of yeast juice; the first described the effect of phosphate on the rate of fermentation of glucose, and the second the separation from the juice by ultrafiltration of an inactive residue which could be re-activated by a soluble, heat-stable coenzyme in the filtrate.

Harden's experiments arose out of an attempt made with Allen Macfadyen to produce an antienzyme by the injection of yeast juice into animals, in the course of which it was found that normal serum increased the fermentation of glucose by yeast juice. In further experiments, Hardon and Young fortunately adopted a volumetric instead of a gravimetrie method, which enabled them to follow the rate of production of carbon dioxide continuously; they found that the filtrate from boiled yeast juice also increased the fermentation, with an initial rapid evolution of carbon dioxide, proportional in amount to the volume of juice added, and a prolongation of fermentation at a slightly higher basal rate. The effect was traced to the phosphates present in the juice, the extra carbon dioxide corresponding to one molecule for every atom of phosphorus added ais orthophosphate; after the fermentation the phosphate was present in a form not precipitated by ammoniacal magnesium eitrate, and presumed to be as an ester. The ester was afterwards identified by Young as fructose diphosphate; later, Harden and Robison found that a hexose monophosphoric ester was also formed which was shown by Robison to be an equilibrium mixture of glucose, fructose and mannose esters.

Harden and Young also dialysed the fresh juice, to find out the effect of the complete removal from the juice of the dialysable substances passing into the filtrate of boiled juice. They used for this purpose the rapid method of ultrafiltration under pressure through a filter of gelatin supported in tho pores of a Chamberland filter candle, which had been devised by C. J. Martin, then director of the Lister Institute. In this way, the juice was separated into a residue and a filtrate, each of which was itsolf incapable of fermenting glucose, but which together fermented it as actively as the original juice. Since soluble phosphates did not activate the residue, it was concluded 